\title{
Research on Whipstock Packer Oriented Perforating Technology
}

\author{
Xing Rendong ${ }^{1, *}$, Wang Feng ${ }^{2}$ \\ ${ }^{1}$ China Oilfield Services Limited (COSL) Tianjin Branch,No.1581, Hai Chuan Road, Tanggu Marine Hi-tech Development Area, Binhai \\ New District, Tianjin, China \\ ${ }^{2} \mathrm{Xi}$ ' an Wuhua Juneng Blasting Equipment Co., Ltd 20th Zhuque Avenue, Xi'an, China
}

\begin{abstract}
Multilateral well drilling and completion technology reduces well development cost and increases effectively the benefit and productivity of oil \& gas well, which is widely used and expanded in recent years at home and abroad. Whipstock packer oriented perforating technology, a critical step in multilateral well drilling and completion, is for perforating whipstock packer and communicating lower branch wellbore. This technology meets the higher requirement of orientation and accuracy of penetration, perforator being able to perforate whipstock packer but not perforate outer casing of whipstock, and also meets complicated operation process.
\end{abstract}

\section{Introduction}

As for petroleum exploitation, multilateral well technology contributes to set a reasonable development program, so as to develop multilateral well effectively with lower cost. Considering from drilling, all branch wells have a common wellbore and upper well section, so this technology will greatly reduce drilling cost and land occupation, and also contribute to environment protection. Besides reducing cost, the multilateral well technology can also increase production rate and ultimate recovery, improve oil drainage mode and increase reserves. It has a great development prospect. In multilateral well completion technology, whipstock oriented perforating has a particularly effect on communicating upper and lower branch wellbore. That is, lower branch wellbore's drilling and completion proceeds firstly, after that lowering down the whipstock packer at the upper branch wellbore depth, then proceeding upper branch wellbore's drilling and completion; after that lowering down perforator and perforating upon whipstock packer, communicating lower branch wellbore and lowering down production tube, so as to accomplish joint exploitation of multilateral well ${ }^{[1]}$.

Whipstock packer oriented perforating is a synthesis technology, with a high technical difficulty and strict process requirement, which designs every technical parameters based on well condition and determines perforating parameters by ground simulation test. This technology meets the higher requirement of orientation, accuracy of penetration and strictness of entry hole, and also meets complicated operation process ${ }^{[2]}$.

Use a two-column format, and set the spacing between the columns at $8 \mathrm{~mm}$. Do not add any page numbers.

\section{Wihpstock Structure and Requirement of Perforating Parameter}

\subsection{A. Multilateral Well Completion Technology}

Multilateral well is that drilling two or more branch wellbore (second stage wellbore) in an original wellbore. The original wellbore could be vertical well, oriented well or horizontal well. Multilateral well has various types, such as overlay type, reversed type, etc., which can be optimized selected according to well reservoir.

In 1997, technical experts on multilateral well from the world major oil company and service company had a communication. They appointed a multilateral well system, that is, TAML (Technology Advancement Multi Laterals) stages. TAML evaluates the technology and stages of multilateral well based on its three features: Connectivity, Isolation and Accessibility. Completions of multilateral well completion is divided into $1 \sim 6 \mathrm{~S}$ as follows.

(1) Grade 1 completion: Original wellbore and branch wellbores are all uncased. During well completion, different reservoir will not be separated and pressure difference among reservoir will not be disposed.

(2) Grade 2 completion: Original wellbore is cased and cemented; branch wellbores are uncased or only completed by sieve tube, not cemented.

(3) Grade 3 completion: Original wellbore and branch wellbores are all cased; original wellbore is cemented, but branch wellbores are not.

(4) Grade 4 completion: Original wellbore and branch wellbores are all cased and cemented at joint position.

(5) Grade 5 completion: Having the joint technology features of Grade 3 and Grade 4 branch wellbore, it also adds a completion machine for pressure seal at joint position of branch wellbore's screen pipe and original 
casing; original wellbore is totally cased and joint is hydraulic isolated.

(6) Grade 6 completion: Pressure at joint and wellbore pressure is the same which is an entirety pressure. It can be acquired by lowering down casing, does not need downhole completion tools.

(7) Grade 6S completion: Using downhole divider or downhole wellhead device; mainly using a downhole double-casing head as the wellhead to divide a large diameter original wellbore into two small equant branch wellbore $^{[3]}$.

Currently, whipstock packer oriented perforating technology is mainly used in Grade 5 completion. The wellbore structure of Grade 5 completion is showed as Fig 2. Taking Grade 5 completion multilateral well's whipstock as the example, this paper will discuss the perforating parameter and operation technology.
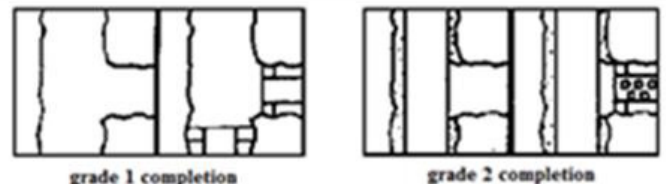

grade 2 completion
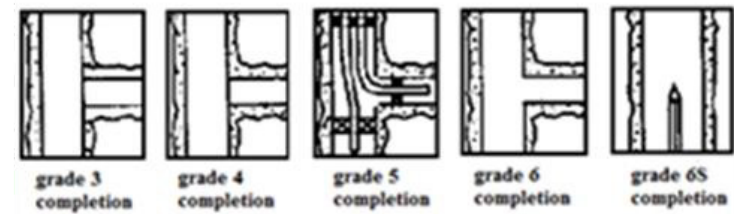

Fig1 Multilateral well TAML grade diagram

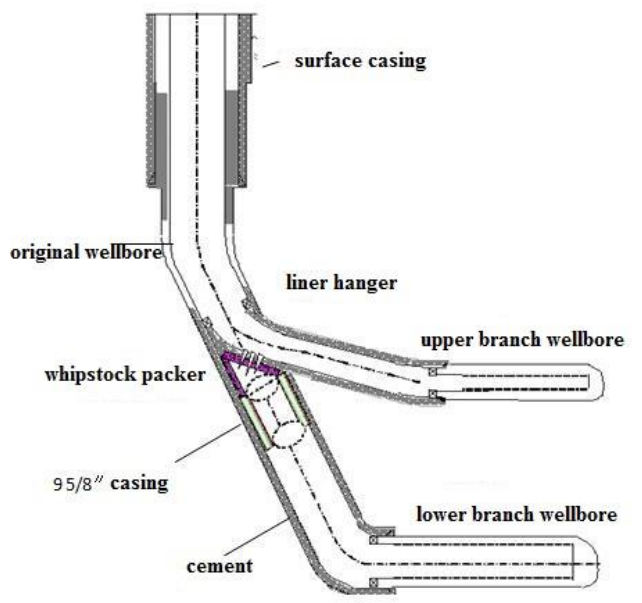

Fig2 Wellbore Structwre of the Grade5 Completiong

\subsection{Structure of Whipstock Packer}

In branch wellbore, the mostly used whipstock packer is hollow whipstock. Its structure is as Fig 3. This type of whipstock connects direction sub (UBHO Sub / MWD $\mathrm{Sub}$ ) on ground, lowering down by drilling rig to preset depth. After adjusting orientation, operator pressurizes on ground and sets packer, meanwhile, releases loading tool and raising drilling rig upon whipstock. On account of the restriction of whipstock structure, the perforating area could only be between $\mathrm{C}$ and $\mathrm{D}$. Radioactive isotope mark could be loaded at both ends of the area before perfortor running down, so as to accomplish an accurate positioning.

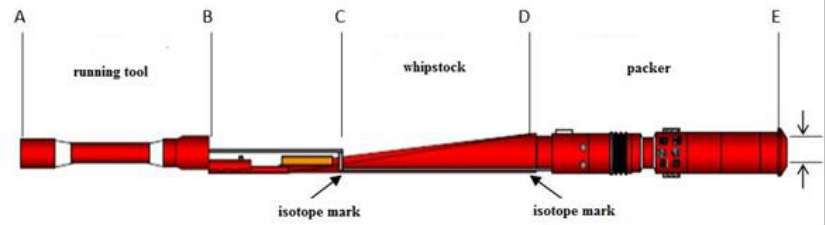

Fig3 Whipstock Packer

\subsection{Requirement of Perforating Design}

(1)To communicate branch wellbore and original wellbore, it is required that perforating gun, branch wellbore casing, cementing and whipstock cover board shall be perforated successively, and to prevent wellbore losing, perforating cannot damage the original wellbore casing of outer whipstock.

(2)The perforator shall be positioned accurately in whipstock perforating area and perforating azimuth error at tool surface shall be $\pm 10^{\circ}$.

(3)To increase oil recovery, the total area of effective perforating entry hole on whipstock cover board shall be more than the area of minimum inner diameter of lowered down production tube.

(4)Because functional dielectric material is different and whipstock changes gradually along angular surface, penetration of perforating charge shall be considered and simulation test of practical well condition is needed.

\section{Selections of Perforator And Simulation Test}

Based on multilateral well' s structure and setting status of whipstock packer, it is required that perforator shall perforate 7 " branch wellbore casing, $95 / 8$ " cover board of whipstock packer and cementing ring between them, but it shall not perforate $95 / 8^{\prime \prime}$ casing of original wellbore, besides that, the effective perforating area (unit entry hole*hole quantity) on whipstock cover board shall be more than the area of minimum inner diameter $\left(2.313^{\prime \prime}\right)$ of production tube in original wellbore.

\subsection{Perforating Gun}

Based on casing dimension of branch wellbore, the 5 " perforating gun is selected, $2.3 \mathrm{~m}$, with a $2 \mathrm{~m}$ effective perforating length, phasing $0^{\circ}$, density $16 \mathrm{shot} / \mathrm{m}$, charge distance $62.5 \mathrm{~mm}$, can be loaded with 32 pieces of perforating charge.

\subsection{Perforating Charge}

Type 127 Big Hole perforating charge is used, loading with normal temperature RDX and $39 \mathrm{~g}$ explosive weight. Shape structure is as Fig 4 and loading structure is as Fig 5.

\subsection{Simulation Test of Single Perforating Charge and Result}


Based on practical well condition, the simulation test device for single perforating charge is designed as Fig 6 . Targets for perforating successively are scallop thickness of perforating gun, water in the gap between perforating gun and casing, 7 " casing thickness, cement and whipstock cover board and whipstock back board. Therein, the gap of whipstock cover board and side wall is between 0.769" (19.53mm) and 4.26" (108.20mm), and the thickness of whipstock back board is 1 " (25.4mm).

(1)Casing gap (gap spacer 1): simulating liquid thickness between scallop of perforating gun and $7^{\prime \prime}$ casing, setting it to be $6.5 \mathrm{~mm}$.

(2)ID of whipstock (gap spacer 2): simulating liquid thickness between scallop of whipstock cover board and whipstock side wall, setting it to be $25.9 \mathrm{~mm}$.

(3)Cement: Simulating the thickness of cement, setting it to be $25.0 \mathrm{~mm}, 35.5 \mathrm{~mm}, 61.0 \mathrm{~mm}$ and $40.0 \mathrm{~mm}$.

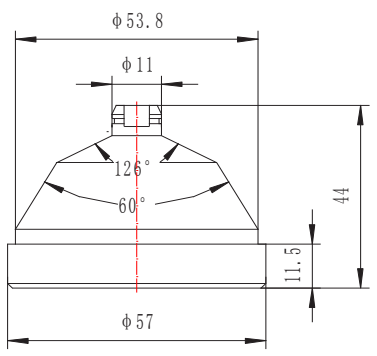

Fig 4 Shape structure of perforating charge

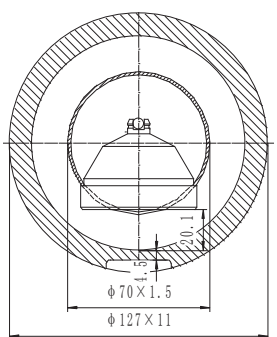

Fig 5 Loading structure of perforating charge
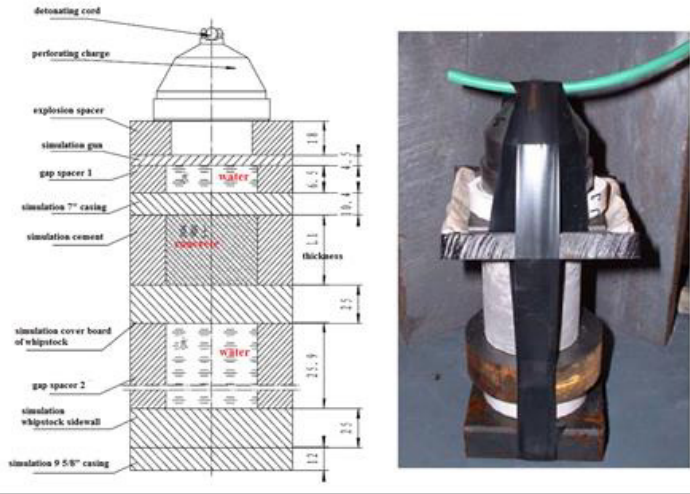

Fig6 Target Test (minimum gap)

\subsection{Test Data and Result}

Based on functional target analysis of perforator and practical perforating status, simulation test under different status is performed, showing as Table 1. Test result based on Table 1's simulation test is as Table 2 .
Table 1 Status Parameter of Simulation Test

\begin{tabular}{|c|c|c|c|c|c|c|c|c|c|c|}
\hline $\begin{array}{l}\text { Status } \\
\text { group }\end{array}$ & $\begin{array}{l}N \\
0\end{array}$ & $\begin{array}{c}\text { Explosi } \\
\text { on } \\
\text { spacer } \\
\text { (mm) }\end{array}$ & $\begin{array}{l}\text { Simulati } \\
\text { on } \\
\text { thicknes } \\
\text { s of gun } \\
\text { (mm) } \\
\end{array}$ & $\begin{array}{c}\text { Simulati } \\
\text { on } \\
\text { casing } \\
\text { gap } \\
(\mathrm{mm}) \\
\end{array}$ & $\begin{array}{c}\text { Simulati } \\
\text { on 7" } \\
\text { casing } \\
\text { thicknes } \\
s(\mathrm{~mm}) \\
\end{array}$ & \begin{tabular}{|c|} 
Simulati \\
on \\
cement \\
thicknes \\
$\mathrm{s}(\mathrm{mm})$ \\
\end{tabular} & \begin{tabular}{|c|} 
Simulation \\
thickness of \\
whipstock \\
cover board \\
(mm)
\end{tabular} & \begin{tabular}{|c} 
Whip \\
stock \\
ID \\
$(\mathrm{mm})$ \\
\end{tabular} & $\begin{array}{c}\begin{array}{c}\text { Simulation } \\
\text { thickness of } \\
\text { whipstock } \\
\text { side wall } \\
(\mathrm{mm})\end{array} \\
\end{array}$ & $\begin{array}{c}\text { Simulation } \\
95 / 8^{\prime \prime} \\
\text { casing } \\
\text { thickness } \\
\text { (mm) } \\
\end{array}$ \\
\hline I & & \multirow{4}{*}{18} & \multirow{4}{*}{4.5} & \multirow{4}{*}{6.5} & \multirow{4}{*}{10.4} & 35.5 & \multirow{4}{*}{25.4} & \multirow{4}{*}{20} & \multirow{4}{*}{25.4} & \multirow{4}{*}{12} \\
\hline II & $\frac{3}{4}$ & & & & & 61 & & & & \\
\hline III & 6 & & & & & 40 & & & & \\
\hline IV & \begin{tabular}{|l|}
7 \\
8
\end{tabular} & & & & & 25 & & & & \\
\hline
\end{tabular}

Table 2 Test Result

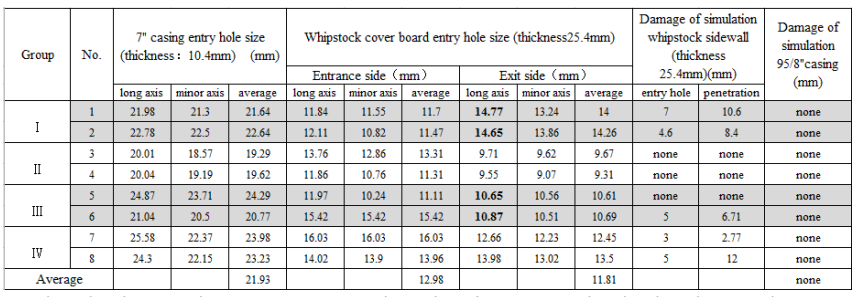

Calculating the test result, it is concluded that the effective perforating area (S1) on whipstock cover board is larger than the flowing area (S2) of original wellbore production tube.

$$
\frac{S 1}{S 2}=\frac{\pi * 11.81^{2}}{\pi *(2.313 * 25.4)^{2}}>1
$$

\section{Operation Process}

\subsection{Introduction of Operation Process}

TCP (tubing conveyed perforating) oriented perforating technology is used in whipstock packer perforating. In this perforating technology, pressure actuated firing head is connected at the top of perforating gun, and tubing short circuit, X-over, UBHO Sub, 3 1/2" drilling pipe, isotope sub (depth sub) and drilling rig are connected to well mouth. All downhole tools must be connected reliably before running down perforating string. Included angle between perforator and orientation key of oriented sub must be measured accurately. It cannot rotate between them. The distance between the first perforating charge at bottom gun and isotope sub should be measured and will not change in wellbore ${ }^{[4]-[6]}$.

TCP oriented perforating technology runs down perforator into preset depth (Fig 8) based on perforating string (Fig 7). After that, running down wireline correlation apparatus to correct depth; calculating the distance $(Z)$ between isotope sub and isotope mark on the top of whipstock packer by calculating isotope sub's depth, meanwhile, adjusting amount (Y-Z-X) of perforating string is concluded. The perforator shall be located at perforating depth and error shall be controlled in $0.2 \mathrm{~m}$. Then running down a Gyro with guide device by wireline; the orientation of orientation key should be measured when the guide device of Gyro inserting in the orientation key of orientation sub and being fixed; adjusting perforating orientation by rotating tube strings on ground, and pressurizing to initiate perforator after the perforating orientation being confirmed ${ }^{[7]}$. 


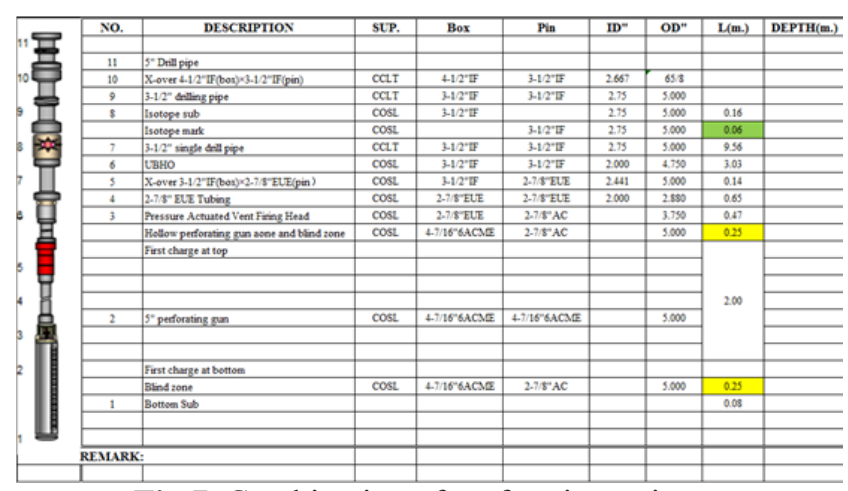

Fig 7 Combination of perforating string

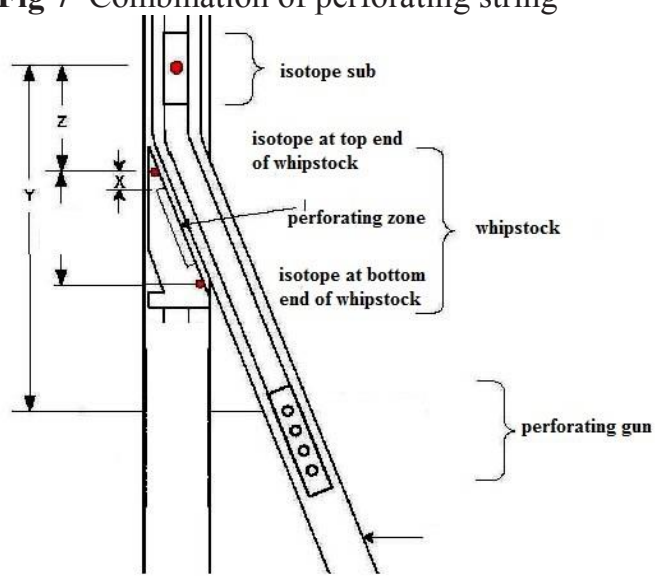

Fig8 Perforating String before depth correction

In that operation process, the function of pressure actuated firing head is to initiate perforator by pressurizing on ground and also to open circulation hole for circulation well killing after communicated lower branch wellbore; the function of tubing short circuit is to remain enough space at the bottom after the guide device of Gyro inserted in the orientation key of UBHO sub ${ }^{[8]}$; the function of UBHO sub is to guarantee the accuracy of perforating orientation by measuring included angle between perforator orientation key on ground and measuring orientation of the orientation key in downhole; the function of isotope sub is to accurately locate the depth of perforating string.

\subsection{Main Steps of Operation Process}

(1)Running down perforating strings: locking phasing mark of whipstock oriented perforating system with oriented sub, then running down it to desired perforating zone by tubing.

(2)Wireline depth correction: When the perforating string is run down to desired depth, GR/CCL combination is run down for wireline depth correction. Perforating gun needs to be below the whipstock; isotope sub must not overlap with isotope of whipstock; CBL/GR/CCL logging Fig or open-hole GR logging material shall be supplied by the owner.

(3)Adjusting perforating string to designed depth: Adjusting perforating string to designed depth based on measuring result.

(4)Orientation measuring: Running down Gyro to measure orientation after adjusted perforating string ${ }^{[9]}$.
(5)Orientation adjusting: Based on measuring result of Gyro, rotating tubing string repeatedly to transfer torque to perforator, so as to adjust orientation of string.

(6)Orientation confirmation: After adjusted perforating orientation, the Gyro shall be run down again to measure orientation. It meets requirement if the orientation error is with the scope of $+/-10$; it is required to adjust orientation again if the orientation error is more than $10^{\circ}$. (7)Pressurizing and initiating: Pressurizing from well mouth to initiate perforator under the command of supervisor.

(8)Lifting perforating string and releasing perforating gun.

\subsection{Announcements during Operation}

To guarantee the preparation and safety of operation, the announcements below shall be considered.

(1)Perforating string shall run down after drifting, flushing and confirmation of stabilization of well loss.

(2)Tubing strings must be drift diameter checked. Measuring apparatus and Gyro shall be reliably run down to designed depth.

(3)It needs to be guaranteed that all downhole tools must be connected reliably, preventing screw loose at connection and dropping down.

(4)Speed of tripping must be smooth and steady. Drastic running or cease during tripping is forbidden.

(5)Any object needs be prevented from dropping down into wellbore. If any object dropped down, operator shall report to supervisor to avoid bigger loss ${ }^{[10]}$.

(6)Load fluid need to be poured every three tubes' running. After full poured, it continues to dripping, avoiding over value of pressure difference from inside and outside tubing.

(7)The distance between first perforating charge of top perforator and isotope mark must be accurately measured. It should confirmed by perforating engineer and supervisor.

(8)It requires that lifting and running tubing strings repeatedly to transfer torque to perforator when rotating tubing string on ground for orientation adjustment, and running down Gyro again to measure perforating orientation if it is under allowable error scope.

\section{Conclusion}

Whipstock packer oriented perforating technology is currently a new operation technology in China, with little operation experience. Requiring high techniques, with complicated process and high risk, this technology is acknowledged as a highly difficult technology in industry. Based on field operation experience accumulation cooperated with international technology, this paper comes to a conclusion that according to test data of perforating charge and optimizing of perforating string, this technology will reduce influence factors of orientation measurement, enhance operation efficiency and lower operation risk. 


\section{References}

[1] Ya JS,Huang JH,Phase Behavior of Sphere-Forming Triblock Copolymers in Films, Proceedings of 2011 World Congress on Engineering and Technology(CET 2011) VOL04. 19 (2011) 6-9.

[2] C SRINIVASANN,Variation of Flow Field Around Twin Cylinders with and Without the Outer Perforated Cylinder, Numerical Study. 3(2016) 3-4.

[3] ZHAO X, Yang JU, Yang Y, Sun SU, Gong WB, Impact of hydraulic perforation on fracture initiation and propagation in shale rocks, Science China (Technological Sciences),.02(2016) 10-13.

[4] Li JF,Eric Diggins.A proposed multilateral welt classification matrix. World Oil, 1997 : 107.

[5] Mic D.Burnaman,S Smith Shale Gas Well Completions and Maximizing Gas Recoveries. China Petroleum Exploration , 03(2009),12-15.

[6] Li Y,Wang XN,Zhang Dj,Control strategies for aircraft airframe noise reduction. Chinese Journal of Aeronautics , 01(2013),6-10.

[7] Modeling natural convection heat transfer from perforated plates. Journal of Zhejiang University-Science A(Applied Physics \& Engineering),03(2009),12-15.

[8] Qiu WJ,Li SB, Yong-yun Ji; Lin Xi Zhang SELF-ASSEMBLY OF LINEAR ROD-COIL MULTIBLOCK COPOLYMERS. Chinese Journal of Polymer Science,09(2013),40-45.

[9] Lin LM,Zhong XF,WU YX Effect of Peak Perforation on Flow Past A Conic Cylinder at $\mathrm{Re}=100$ :Drag, Lift and Strouhal Number. China Ocean Engineering,06(2017),4-8.

[10] Modified Atmosphere Packaging Enhances Postharvest Green Celery Quality. Collection of Extent Abstracts of 2004 CIGR International Conference(Volume.1),11(2004),10-14. 